${ }^{1}$ Department of Restorative Dentistry, Faculty of Dentistry, University of São Paulo, São Paulo, Brazil.

${ }^{2}$ Universitary Center Unichistus, Fortaleza, Ceará, Brazil.
Corresponding author:

Giulio Gavini

Dept. of Restorative Dentistry of Faculty of Dentistry, University of São Paulo

Av. Prof. Lineu Prestes, 2227 -

Cidade Universitária, São Paulo, SP, Brasil

e-mail: ggavini@gmail.com phone: 55-11-30917839

Received: June 04, 2018

Accepted: April 28, 2019

\section{Influence of cross-section and number of use in cyclic fatigue resistance of rotary instruments}

\author{
Luís César Brisighello ${ }^{1}$, George Táccio de Miranda \\ Candeiro ${ }^{1,2}$, Luiza Riomar Paz ${ }^{1}$, Hermano Camelo \\ Paiva ${ }^{1}$, Giulio Gavini ${ }^{1, *}$
}

Aim: The aim of present study was to evaluate if the crosssection and the number of use have influence in cyclic fatigue resistance of rotary files. Methods: K3 Endo (group K) and EndoSequence (group E) files, 25/.04, $25 \mathrm{~mm}$, were subdivided into 3 subgroups ( $n=12$ ) according to the number of uses, 1 , 3 and 5 uses, totalizing 72 files. The files were submitted to dynamic assays device moved by an electric engine, using $300 \mathrm{rpm}$ of speed that permitted the reproduction of pecking motion. The files run within a temperate steel ring's groove, simulating an instrumentation of a curved root canal with 40-degrees and $5-\mathrm{mm}$ of curvature radius. The fracture of file was detected by sensor of device and the time and the number of cycles was acquired. The data were analyzed statistically by two-way ANOVA ( $p<0.05)$. Results: There were no statistical significant differences in regard to the number of uses ( $p>0.05)$. K3 Endo files showed greater resistance to cyclic fatigue than EndoSequence instruments $(p<0.01)$. Conclusion: It may be concluded that the cross-section of instruments presented significant influence in cyclic fatigue resistance and the number of uses up to 5 times had no influence in cyclic fatigue resistance in both NiTi rotation systems evaluated.

Keywords: Fatigue. Nickel. Titanium. Dental instruments. 


\section{Introduction}

The major aim of endodontic treatment is to maintain or to promote the periapical health, with the maximum elimination of microorganisms of the root canals system. Therefore, the chemomechanical preparation plays an important role in the cleaning and shaping of root canals with the use of several instruments and chemical auxiliary substances.

In curved canals, there are some physical and mechanical challenges that difficult the correct modeling and the effective bacterial elimination. To carry out a better instrumentation of these root canals, rotary NiTi files are employed due its superelasticity and shape memory effects. These instruments allow the dentist to efficiently prepare the root canal with significantly less zipping and ledging and with minimal transportation towards the outer aspect of the curve ${ }^{1-3}$. The vast majority of the studies uniformly describe good maintenance of curvature even in severely curved root canals ${ }^{3-5}$.

Despite greater flexibility and torsion resistance, fracture is the major concern in NiTi files, especially after prolonged use ${ }^{6}$. Unfortunately, most of these fractures occur unexpectedly, with no sign of permanent deformation. Cyclic fatigue of the alloy, with successive tension and compression loads on the curved areas of the root canal, can be the most destructive form of cyclic load ${ }^{7}$. Therefore, most cases of mechanical failure of NiTi rotary files during clinical use have been associated with cyclic fatigue ${ }^{8}$.

The frequency of use of rotary NiTi files and the file cross-section are parameters that might affect the cyclic fatigue resistance of these instruments ${ }^{9,10}$. Few studies have investigated dynamic cyclic fatigue using an apparatus ${ }^{11-13}$ that simulates the pecking motion even as the use of this movement during instrumentation by NiTi rotary files appears to significantly extend the life of the instrument. Therefore, the purpose of this study was to assess the cyclic fatigue behavior of two NiTi rotary files with different cross-section, K3 Endo (SybronEndo, Orange, USA) and EndoSequence (Brasseler USA, Savannah, GA, USA), submitted to repeatedly used in simulated curved canals, using an experimental cyclic fatigue testing apparatus that simulates the pecking motion in curved canals. Thus, the null hypothesis is that rotary NiTi systems with different cross-section and that the repeat uses of instruments have no influence in resistance to cyclic fatigue during instrumentation in curved canals performing pecking motion.

\section{MATERIALS AND METHODS}

Three hundred twenty simulated canals were constructed using size 15 silver points as templates. The annealed silver points were pre curved to create artificial canals with angle of curvature of $40^{\circ}, 5 \mathrm{~mm}$ of radius curvature and $21 \mathrm{~mm}$ of length, and the beginning of the curve was positioned $14 \mathrm{~mm}$ from the canal orifice. These simulated canals were constructed using self-curing epoxy resin (Araldyte LY 1316 Ciba, São Paulo, SP, Brazil) in the proportion of $100 \mathrm{~g}$ of resin to $13 \mathrm{~g}$ of catalyst (HY 1208 Ciba, São Paulo, SP, Brazil). To prevent the formation of bubbles, the mixing of the resin with the catalyst was carried out by the vacuum spatulate Model A 300 
(Polidental, São Paulo, SP, Brazil). Clear spectrophotometer cuvettes (STARNA, UK) retained the epoxic resin that was poured around the silver points ${ }^{14}$.

A total of thirty-six K3 Endo (group K) and thirty-six EndoSequence (group E) files, size \#25, taper 0.04 were divided into four subgroups of 12 specimens each, based on number of repetitions (1, 3 and 5 times) to which the files would be submitted. The files were used with an electric motor at $300 \mathrm{rpm}$ with $2.0 \mathrm{~N} . \mathrm{cm}$ of torque. A 16:1 reduction contra angle was attached to the electric motor.

To reduce interoperator variables, each preparation was conducted by the same operator, with wide experience of the preparation technique for shaping root canals with the rotary NiTi files, prepared all the simulated curved root canals using the pecking motion, that consists in exerting enough pressure so that the instrument will move forward millimeter by millimeter, followed by light backward movements until the desired depth is reached. During the preparation of resin blocks canals, the operator was unaware of the number of times that the instrument was being used, nor the driven torque.

Prior to preparation and after the use of each instrument, copious irrigation with $3 \mathrm{ml}$ of $1 \% \mathrm{NaOCl}$ solution was performed using disposable syringes and Endo-Eze irrigation needle (Ultradent Products Inc., South Jordan, UT, USA). During the instrumentation procedure, approximately $12 \mathrm{ml}$ of irrigant was used per block.

After each cycle of use the files tested were examined under a magnification of 10X. If distortions or breakage in the flutes were observed, the instrument was discarded. Based on this evaluation, no instrument has been discarded. Then they were washed with tap water and soap, dried with paper towels, placed in an envelope and autoclaved for 20 minutes at $121^{\circ} \mathrm{C}$ temperatures.

Cyclic fatigue testing was performed with a custom-made apparatus (Fig. 1) specifically designed to allow dynamic testing by simulating the pecking motion, made essentially of aluminum, according to Gavini et al. ${ }^{15}$ (2012).

An electric motor handpiece (Driller, São Paulo, Brazil) was used with a contra-angle of 16:1 (NSK, Kanuma, Japan). Firstly, the micromotor/contra-angle handpiece was secured to the support arm in a parallel position to the apparatus base. Then, the file was secured to the contra-angle handpiece, ensuring correct locking. The electric motor was calibrated to run at a speed of 300 rpm and torque identical to that used during the preparation of simulated canals.

Platforms were moved using the grading rings until reaching a position that allowed the file to remain curved and free to rotate between the cylinder and the steel jig, thus simulating rotary instrumentation of a canal with a 40 -degree, $5-\mathrm{mm}$ radius curvature. Care was taken to ensure that the instrument was well positioned in the cylinder groove, so as to avoid file displacement. The instrument tip remained visible throughout the experiment, touching the sensor when the maximum displacement of the pneumatic system was achieved.

With the file adequately positioned, the main switch turned on, the electric motor was powered, and simultaneously turned on the pneumatic switch. With that, the whole set micromotor/contra-angle/file were powered by the pneumatic system, reproduc- 


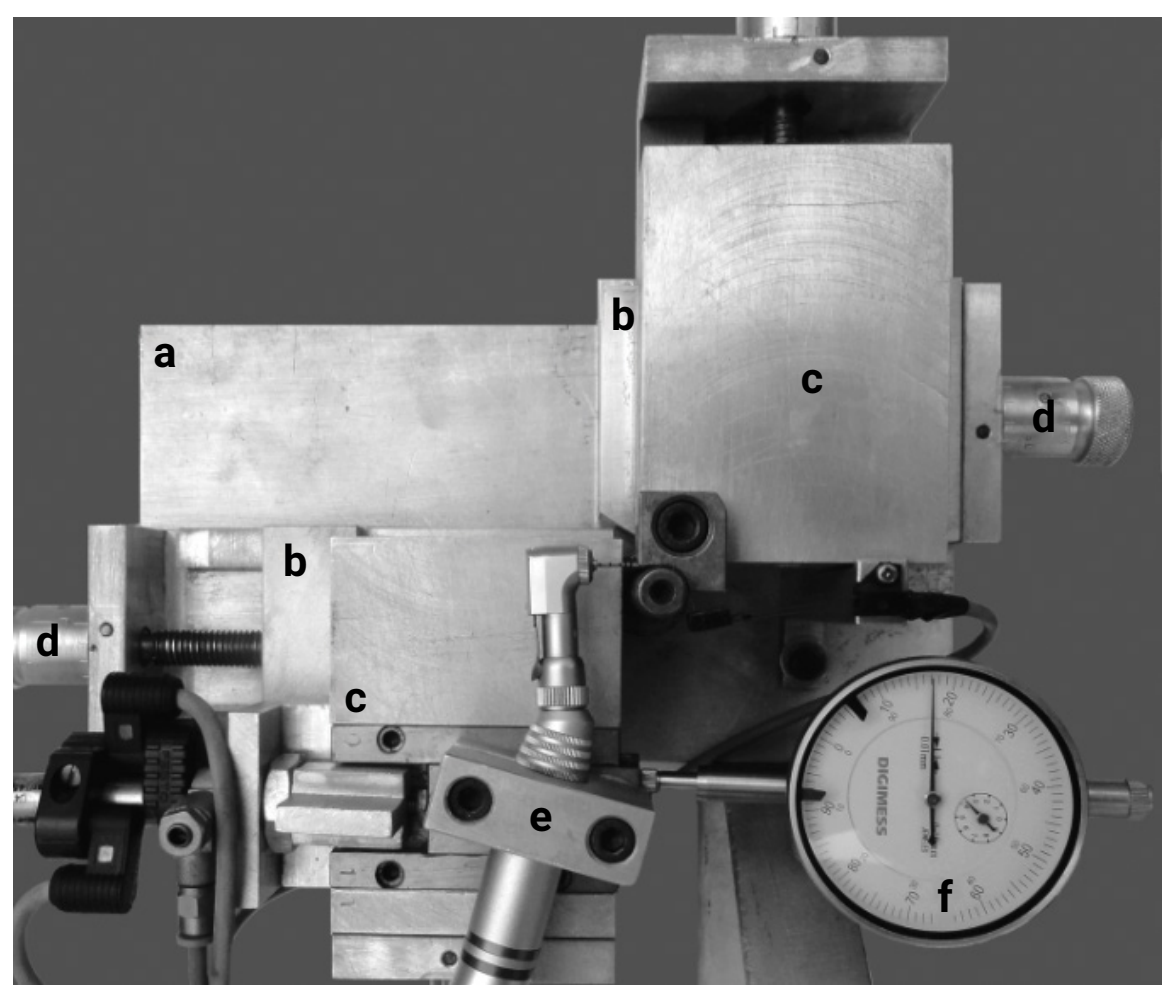

Figure 1. Cyclic fatigue testing apparatus. Letters $a, b$ and $c$ - Rectangular platforms; $d$ - Grading rings; $e-$ Mechanical arm with locking ring to support micromotor/contra-angle/file; $f$ - pneumatic cylinder to reproduce reproducing the pecking motion.

ing the pecking motion, with a $2 \mathrm{~mm}$ each movement forward and backward, where the file slide in the groove created on the ring made of tempered steel. This movement was repeated at a speed of one cycle per second. The fracture of the instrument was easily detected by the sensor, at moment which the counter and timer were stopped. Testing time was registered with a digital stopwatch (Casio, Tokyo, Japan), started at the moment the motor was turned on and stopped at fracture detection. This procedure was sequentially repeated for all groups.

After completion of all tests, the mean time to failure observed in each group was recorded in seconds.

Because our study included independent set of samples with normal distribution and equal variances, the ANOVA and the Student $t$ test were employed to assess the presence of statistically significant differences $(p<0.01)$. Statistical analysis was performed with SPSS 17.0 statistical software (SPSS, Chicago, IL, USA)

\section{RESULTS}

Fatigue resistance data were assessed with regard to central tendency (means) and dispersion (standard deviation). The effect of number of uses of the files on cyclic fatigue was not statistically significant $(p=0.3592)$ in both rotation systems. The instruments with 1, 3 and 5 numbers of uses, behave similarly in regard to cyclic 
fatigue. On the other hand, K3 Endo files showed significantly greater resistance to cyclic fatigue $(p=0.0146)$ than EndoSequence files. Table 1 shows fracture data obtained within each group.

Table 1. Mean of cycles to occur the fracture (standard deviation), according to the number of uses and type of file used in each experimental group.

\begin{tabular}{lcc}
\hline Uses & K Group & E Group \\
\hline 1 & $674.60^{\mathrm{a}}(78.25)$ & $333.35^{\mathrm{b}}(70.90)$ \\
\hline 3 & $597.50^{\mathrm{a}}(64.60)$ & $317.90^{\mathrm{b}}(83.05)$ \\
\hline 5 & $547.90^{\mathrm{a}}(105.20)$ & $255.85^{\mathrm{b}}(68.95)$
\end{tabular}

Different letters indicate the presence of statistically significant differences $(p<0.01)$

\section{DISCUSSION}

In present study, the null hypothesis was accepted in regard to number of uses of instruments, however was rejected in regard to rotary systems.

The present study assessed the cyclic cyclic fatigue resistance of $\mathrm{K} 3$ Endo and EndoSequence files size \#25, taper 0.04 submitted to different number of uses, using an experimental cyclic fatigue testing apparatus that simulates the pecking motion. File size (\# 25) and taper (0.04) were chosen for being different from those established in the ISO standard and compatible with the clinical instrumentation of apical thirds in curved canals.

The option for K3 Endo and EndoSequence files was based on idea that the cross-sectional area of the files may influence strongly the cyclic fatigue resistance ${ }^{16}$, fact that happens throughout the $16 \mathrm{~mm}$ of the working portion of these instruments. K3 Endo files present a positive rake angle with three radial lands and a relatively large cross-sectional area ${ }^{17}$. EndoSequence has a triangular cross-section, without radial lands and with alternating contact points (ACP) along the instrument's shank. The use of ACP allows the file to remain centered in the canal, while simultaneously reducing the torque requirements. The lack of radial lands provides a sharper instrument as a result of a decreased thickness of metal, thereby providing a more flexible file. Combined with a precision tip, the alternating contact points provide an efficient instrument that will not transport the canal. The EndoSequence file undergoes electropolishing and the result is visible in its mirror-like finish that remains sharper longer and stays cleaner during use. Some authors observed that electrochemical polishing did not inhibit the development of microcracks in EndoSequence NiTi files ${ }^{18}$ and $\mathrm{K} 3$ Endo files ${ }^{19}$.

The design of the cross-sectional will influence the file's flexibility and how much lateral resistance is generated when the file is working within the canal9,20,21. File designs that incorporate radial lands, in an attempt to reinforce the cross-section of the file and thereby decrease file separations. This fact also will increase significantly the percentage of contact with the canal wall and subsequently increase lateral resis- 
tance. Radial lands that increase the stiffness of a file decrease its flexibility in curved canals. The developers state that removing radial lands increases cutting efficiency, increases flexibility, and reduces "drag," therefore lowering the torque requirements of the files ${ }^{20,21}$

Files ground from triangular blanks will have greater flexibility than those with wide radial lands, but may transport the canal if they lack a centering device. Furthermore, those files with a constant pitch have a tendency to create "suck-down", particularly in larger sizes. Suck-down, refers to the tendency of the file to be pulled apically as it engages the canal walls. This results in an increased potential for file separation. Some authors reported a higher rate of fracture in files without radial lands than those instruments with radial lands9,18, agreeing with the present research. In a similar study, Ray et al. ${ }^{9}$ (2007) also observed that EndoSequence files presented significantly lower resistance to fracture than K3 Endo files, with used under 300 and $600 \mathrm{rpm}$.

Mechanical stress of NiTi files is strongly related to the curvature of the root canal and dentin hardness ${ }^{22}$, but it is also proportional to motor torque ${ }^{14,23}$, thus the instrument's cyclic fatigue resistance should decrease with prolonged clinical use ${ }^{23,24}$. Cyclic fatigue occurs at the instrument maximal flexure, when rotating freely inside curved canals, without prior indication of failure ${ }^{15}$. Continuous traction and compression cycles in curved canals are the most destructive form of cyclic fatigue and fracture in endodontic files ${ }^{11,14,25-27}$. Although many studies have assessed cyclic fatigue and the dynamics of NiTi rotary files ${ }^{14,23,28}$, the relationship between force exerted during preparation of the root canal and clinical risk of distortion and fracture of the files has not been properly studied yet.

This study attempted to investigate the mechanisms of pecking motion associated cyclic fatigue test in the breakage of two NiTi rotary instruments. The methodology allowed the instruments to rotate freely at a standardized curvature. Other studies $^{23,24,27}$ have also indicated that these methodological characteristics are the most appropriate ones for the assessment of cyclic fatigue in rotary NiTi instruments, since static tests do not reproduce the real conditions faced in the clinical practice: automated instrumentation systems have been designed to enter the root canal in motion, with previously determined torque and speed values, whereas, the distribution of the load over a large area prolonged the useful life of the instrument. The occurrence of maximum flexion in the same location, in the same point, will decrease the lifetime of the instrument. The continuous strength of tension and compression in the curved area of the root canal can promote a destructive load of NiTi rotary instruments ${ }^{23,26}$.

During the pecking motion, the instruments were always stressed in the curved canals, but the pecking distance gives the instruments a time interval before it once again passes through the highest stress area. According to Li et al. ${ }^{12}$, the pecking motion may be a crucial factor in preventing the breakage of NiTi rotary instruments. Thus, the pecking motion minimizes the stress on instruments into curves, decreasing the chance of occur a fracture. Li et al. ${ }^{12}$ (2002) still recommended that to avoid breakage of a NiTi rotary instrument, appropriate rotational speed and continuous pecking motion in root canals are necessary. 
This study was conducted in simulated canals to reduce the variation in the instrumentation technique and limit the variability of parameters, such as length, width, anatomy, radius and angle of curvature of the canal. The handpiece was never forced apically during instrumentation. With regard to the angle and radius of curvature used, the option for $40^{\circ}$ and $5 \mathrm{~mm}$, respectively, better represents the clinical conditions of a root canal with gradual curvature.

An analysis of the studies that investigated the impact of torque and number of uses on the cyclic fatigue behavior of NiTi rotary files allowed concluding that fracture can be avoided by regularly disposing of files after a few uses, and by using low torque motors, operating below the maximum torque limit of each different NiTi file. The results of this in vitro study must be interpreted critically, and comparisons with the clinical practice must be drawn carefully, because only two of the many variables of root canal preparation were assessed. During this procedure, there are different types of stress from different mechanisms, which are correlated and can affect the useful life of NiTi rotary files.

Although there is still no consensus regarding the number of uses or the maximum torque permitted for each file system. It may be affirmed according to results of this study that K3 Endo and EndoSequence files, size \#25, taper 0.04, can be used at up to 5 times and with a maximum torque of $2 \mathrm{~N} . \mathrm{cm}$, without affecting their cyclic fatigue behavior.

It may be concluded that the cross-section of instruments presented significant influence in cyclic fatigue resistance and the number of use, up to 5 times, had no influence in cyclic fatigue resistance in both NiTi rotary systems analyzed.

\section{REFERENCES}

1. Schäfer E, Florek H. Efficiency of rotary nickel-titanium $\mathrm{K}^{3}$ instruments compared with stainless steel hand K-Flexofile. Part 1. Shaping ability in simulated curved canals. Int Endod J. 2003 Mar;36(3):199-207

2. Schäfer E, Schulz-Bongert U, Tulus G. Comparison of hand stainless steel and nickel-titanium rotary instrumentation: a clinical study. J Endod. 2004 Jun;30(6):432-5.

3. Schirrmeister JF, Strohl C, Altenburger MJ, Wrbas KT, Hellwig E. Shaping ability and safety of five different rotary nickel-titanium instruments compared with stainless steel hand instrumentation in simulated curved root canals. Oral Surg Oral Med Oral Pathol Oral Radiol Endod. 2006 Jun;101(6):807-13.

4. Thompson SA, Dummer PMH. Shaping ability of Quantec Series 2000 rotary nickel-titanium instruments in simulated root canals: Part 2. Int Endod J. 1998 Jul;31(4): 268-74.

5. Thompson SA, Dummer PMH. Shaping ability of Quantec Series 2000 rotary nickel-titanium instruments in simulated root canals: Part 1. Int Endod J. 1998 Jul;31(4):259-67.

6. Yared G. In vitro study of the torsional properties of new and used ProFile nickel-titanium rotary files. J Endod. 2004 Jun;30(6):410-2.

7. Serene TP, Adams JD, Saxena A. Nickel-Titanium instruments: applications in Endodontics. St Lois: Ishiyaku Euroamerica; 1995. 112 p. 
8. Spanaki-Voreadi AP, Kerezoudis NP, Zinelis S. Failure mechanism of ProTaper Ni-Ti rotary instruments during clinical use: fractographic analysis. Int Endod J. 2006 Mar;39(3):171-8.

9. Ray JJ, Kirkpatrick TC, Rutledge RE. Cyclic fatigue of endosequence and K3 rotary files in a dynamic model. J Endod. 2007 Dec;33(12):1469-72.

10. Tygeson YA, Steiman R, Ciavarro C. Comparison of distortion and separation utilizing ProFile and Pow-R nickel-titanium rotary files. J Endod. 2001 Dec;27(12):762-4.

11. Haïkel Y, Serfaty R, Bateman G, Senger B, Allemann C. Dynamic and cyclic fatigue of engine-driven rotary nickel-titanium endodontic instruments. J Endod. 1999 Jun;25(6):434-40.

12. Li UM, Lee BS, Shih CT, Lan WH, Lin CP. Cyclic fatigue of endodontic nickel-titanium rotary instruments: static and dynamic tests. J Endod. 2002 Jun;28(6):448-51.

13. Kawakami DA, Candeiro GT, Akisue E, Caldeira CL, Gavini G. Effect of different torques in cyclic fatigue resistance of K3 rotary instruments. Braz J Oral Sci. 2015 Jun;14(2):122-5.

14. Zelada G, Varela P, Martín B, Bahillo JG, Magán F, Ahn S. The effect of rotational speed and the curvature of root canals on the breakage of rotary endodontic instruments. J Endod. 2002 Jul;28(7):540-2.

15. Gavini G, Caldeira CL, Akisue E, Candeiro GT, Kawakami DA. Resistance to flexural fatigue of Reciproc R25 files under continuous rotation and reciprocating movement. J Endod. 2012 May;38(5):684-7.

16. Sattapan B, Nervo GJ, Palamara JEA, Messer HH. Defects in rotary nickel-titanium files after clinical use. J Endod. 2000 Mar;26(3):161-5.

17. Mounce R. The K3 rotary nickel-titanium file system. Dent Clin North Am. 2004 Jan;48(1):137-57.

18. Herold KS, Johnson BR, Wenckus CS. A scanning electron microscopy evaluation of microfractures, deformation and separation in EndoSequence and ProFile nickel-titanium rotary files using an extracted molar tooth model. J Endod. 2007 Jun;33(6):712-4.

19. Barbosa FOG, Gomes JACP, Araújo MCP. Influence of electrochemical polishing on the mechanical properties of K3 nickel-titanium rotary instruments. J Endod. 2008 Dec;34(12):1533-6. doi: 10.1016/j.joen.2008.08.023.

20. Koch KA, Brave DG. Real World Endo Sequence file. Dent Clin North Am. 2004 Jan;48(1):159-82.

21. Koch K, Brave D. The EndoSequence file: a guide to clinical use. Compend Contin Educ Dent. 2004 Oct;25(10A):811-3.

22. Mesgouez C, Rilliard F, Matossian L, Nassiri K, Mandel E. Influence of operator experience on canal preparation time when using the rotary Ni-Ti ProFile system in simulated curved canals. Int Endod J. 2003 Mar;36(3):161-5.

23. Pruett JP, Clement DJ, Carnes-Jr DL. Cyclic fatigue testing of nickeltitanium endodontic instruments. J Endod. 1997 Feb;23(2):77-85.

24. Yared GM, Bou Dagher FE, Machtou P. Cyclic fatigue of profile rotary instruments after clinical use. Int Endod J. 2000 May;33(3):204-7.

25. Melo MCC, Bahia MGA, Buono VTL. Fatigue resistance of enginedriven rotary nickel-titanium endodontic instruments. J Endod. 2002 Nov;28(11):765-9.

26. Eggert C, Peters O, Barbakow F. Wear of nickel-titanium lightspeed instruments evaluated by scanning electron microscopy. J Endod. 1999 Jul;25(7):494-7.

27. Pessoa OF, Silva JM, Gavini G. Cyclic Fatigue resistance of rotary NiTi Instruments after simulated clinical use in curved root canals. Braz Dent J. 2013;24(2):117-20. doi: 10.1590/0103-6440201302164.

28. Cho Ol, Versluis A, Cheung GS, Ha JH, Hur B, Kim HC. Cyclic fatigue resistance tests of Nickel-Titanium rotary files using simulated canal and weight loading conditions. Restor Dent Endod. 2013 Feb;38(1):31-5. doi: 10.5395/rde.2013.38.1.31. 